\title{
The Interpretation of Science
}

(I) Science in the Making

By Gerald Heard. Pp. 267. (London: Faber and Faber, Ltd., 1935.) 7s. 6d. net.

\section{(2) Science and the Public Mind}

By Benjamin C. Gruenberg. Pp. xiii + 196. (New York and London: McGraw-Hill Book Co., Inc., 1935.) 12s. net.

$\mathrm{I}^{\mathrm{T}}$ has become clear to most thoughtful observers that science itself has reached a crisis no less pregnant than the crisis which developed in the world at large in great measure as the culmination of the rapid and uncontrolled application of mechanical invention and discoveries in physical science. Science is being driven to help to work out a broader philosophy and to combine to make a whole of life or to accept limitations on its own restricted fields of inquiry. The restrictions being imposed under modern dictatorship are merely a foretaste of what will develop more generally, if science does not support reason and assist the other faculties which are needed to establish reason and elaborate a philosophy in which reason is not merely an accident, and understanding, judgment, impartiality, charity as well as tolerance, insight as well as analysis, are absolutely valid.

On the other side, science continues to change our lives and transform almost every condition of living. New forces are continually being released, and unless we can reach an adequate understanding of the new focus science has given us, civilisation will be smashed because we continue to use the new powers for old aims. Only the discovery of superhuman purpose can make man safe against himself when armed with his present superhuman powers.

The closing, in this way, of the gap between our rapid scientific advance and our moral and ethical development demands two things. First, the breakdown of the barriers between the different sciences so as to facilitate co-ordination and secure advance where it is most needed in the interest of the whole race. Secondly, the interpretation of science to the general citizen so that he can visualise scientific advance as a whole and understand its bearing upon the other values and activities of life upon which it impinges and with which he is engaged.

(1) Both tasks demand interpreters and it is the merit of Mr. Gerald Heard's book that, although addressing himself primarily to the layman, he to some extent performs the first task also. In fact, whatever claims the original broadcast talks, on which the book is based, may have had to the title "Science in the Making", in their expanded form, the title is clearly a misnomer. There are no descriptions of technique and singularly little indication of the way in which science is built up ; the book would have been more happily entitled "The Interpretation of Science". Despite a style which some will find mildly irritating, Mr. Heard has done his work well, though his references to Leakey's theories might have been more guarded. $\mathrm{He}$ has at any rate pointed the way, and the book may well inspire some scientific specialists to take a greater interest in science as a whole and in a scientific attitude to life in general. Is it too much to hope that it may induce others to consider more closely the social consequences of their work and to attempt its interpretation?

(2) "If society is to maintain its health and sanity, the public at large must either be trained to accept the guidance and direction of a special class . . . or else it must be trained to take part in the knowledge, the culture, the thought, the concepts upon which its civilisation rests." In these words, Dr. Gruenberg indicates the real choice before us in regard to educational policy and his own reason for presenting his study of the place of science in relation to adult education.

Although much of the material is drawn from American sources, the breadth of vision and the extent of the survey give this book real value to all who are concerned with the problems arising out of the impact of scientific discovery on society and our ability to master the new forces placed at our disposal. Dr. Gruenberg gives an admirable and concise statement of the problems which are involved in the education of society as a whole as to the value of science and its true contribution in thought and life. Whatever may be the fate of democratic government, its fullest possibilities can only be realised through a community thinking continuously and effectively according to the essential scientific method, with all that it implies of wide and clear vision, the recognition of the need for inquiry upon great questions and the settlement of problems upon the basis of facts and logic.

Scientific workers who have any concern with the interpretation of the results of scientific investigations to the community or with the consequences of their own discoveries cannot fail to find Dr. Gruenberg's analysis of the situation highly suggestive whether in treating of the failure of science to reach the public, the means and methods of bringing science before the public, or in his recommendations for future efforts in this field. 